Universidad de Lima

Facultad de Derecho

Carrera de Derecho

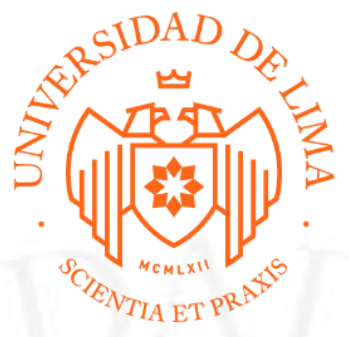

\title{
CIVIL: "INDEMNIZACIÓN POR RESPONSABILIDAD CIVIL EXTRACONTRACTUAL" E INTERNACIONAL: "DERECHOS HUMANOS"
}

Trabajo de suficiencia profesional para optar el Título Profesional de Abogada

\section{Ximena Marcela Delgado Mondragón}

Código 20131774

Lima - Perú

Agosto de 2019 


\title{
CIVIL: "INDEMNIZACIÓN POR RESPONSABILIDAD CIVIL EXTRACONTRACTUAL"
}

Materia: Indemnización por Responsabilidad Civil Extracontractual $\mathrm{N}^{\mathrm{o}}$ de Expediente: 00862-2003-0-1801-JR-CI-65

\section{RESUMEN}

El presente informe explicará los hechos que dieron lugar a la demanda de indemnización por responsabilidad civil extracontractual presentada por el A. A. A., sucesor procesal del B. B. B. B. en contra de C. C. C. S.A. Se analizarán los problemas jurídicos del caso, así como la jurisprudencia, doctrina y las leyes pertinentes. Asimismo, se van a detallar y explicar los argumentos expuestos por ambas partes en el proceso, así como las sentencias emitidas por el Juzgado, la Sala Civil de Lima y lo indicado por la Corte Suprema de Justicia. Finalmente, se va a emitir una opinión personal acerca del caso y las sentencias.

\section{ADMINISTRATIVO: "PROTECCIÓN AL CONSUMIDOR"}

Materia: Responsabilidad Internacional del Estado mexicano por violaciones a los

\author{
Derechos Humanos \\ $\mathrm{N}^{\mathrm{o}}$ de Expediente: Casos 12.496, 12.497 y 12.498
}

\section{RESUMEN}

El presente informe explicará los hechos que dieron lugar a la demanda presentada por la Comisión Interamericana de Derechos Humanos contra los Estados Unidos Mexicanos por Responsabilidad Internacional del Estado por violaciones a los Derechos Humanos. Se analizarán los problemas jurídicos del caso, así como la jurisprudencia, doctrina y las leyes pertinentes. Asimismo, se hará un análisis a detalle de los argumentos expuestos por ambas partes en el proceso, así como las sentencias emitidas, el cumplimiento de las medidas dadas al Estado Mexicano y sus consecuencias en la sociedad. Finalmente, se va a emitir una opinión personal acerca de la sentencia y del caso. 